\title{
Спектры люминесценции мощных светодиодов на основе нитрида галлия в ультрафиолетовой и фиолетовой областях спектра
}

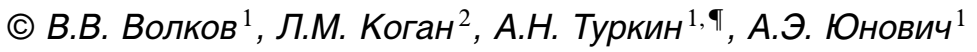 \\ ${ }^{1}$ Московский государственный университет им. М.В. Ломоносова (физический фракультет), \\ 119991 Москва, Россия \\ ${ }^{2}$ Научно-производственный центр „Оптэл“, \\ 105187 Москва, Россия \\ ๑ E-mail: andrey@turkin.su
}

(Получена 23 ноября 2017 г. Принята к печати 11 декабря 2017 г.)

Изучены спектры электролюминесценции мощных светодиодов на основе $p-n$-гетероструктур типа $\mathrm{InGaN} / \mathrm{AlGaN} / \mathrm{GaN}$, излучающих в видимой коротковолновой и ультрафиолетовой областях спектра (диапазон от 370 до 460 нм). Форма спектров описана моделью, учитывающей двумерную комбинированную плотность состояний и флуктуации потенциала. В спектрах излучения обнаружены дополнительные длинноволновые пики. Мощность излучения ультрафиолетовых и фиолетовых светодиодов достигает 233 мВТ при токе 350 мА, внешний квантовый выход - до 23\% в максимуме (вблизи тока 100 мА).

DOI: $10.21883 /$ FTP.2018.10.46456.8775

\section{1. Введение}

Развитие физики и технологии соединений $\mathrm{A}^{\mathrm{III}} \mathrm{B}^{\mathrm{V}}-$ нитридов алюминия, индия и галлия $(\mathrm{AlInGaN})-$ показало, как научные исследования и технологические разработки новых материалов, а также реализация приборов на их основе приводят к экономически эффективному внедрению этих результатов в промышленность. Примером являются светодиоды (СД) белого свечения, на основе $\mathrm{GaN}$ и его твердых растворов, технология которых за последнее десятилетие прошла путь от создания единичных экземпляров до производства приборов массового применения [1,2].

В последние годы наблюдается значительный прогресс в создании СД для коротковолновой части спектра (ультрафиолетовых и фиолетовых) на основе AlInGaN [3-5]. Исследования были направлены как на продвижение в ультрафиолетовую (УФ) область, так и на увеличение мощности излучения диодов. Спектральный диапазон УФ СД на основе гетероструктур AlInGaN лежит в пределах длин волн $\lambda=210-400$ нм; их внешний квантовый выход излучения достигает $\eta_{e}=0.13-2.78 \%$ вблизи $\lambda=250-280$ нм. Оптическая мощность и внешний квантовый выход УФ СД падают при уменьшении $\lambda$, и для большинства практических применений необходимо их увеличивать.

Применение полупроводниковых источников излучения в коротковолновом диапазоне востребовано в фотолитографии, в приборах для обнаружения токсичных веществ, в биомедицинских исследованиях, в приборах для очистки, стерилизации воды и воздуха, в устройствах с высокой плотностью хранения данных в оптическом диапазоне, а также для связи в условиях непрямой видимости.

Миниатюризация устройств, обеспечение их максимальной эффективности и безопасности для здоровья человека и окружающей среды требуют разработки новых источников излучения взамен традиционно используемых для УФ диапазона газоразрядных ламп.

Цель настоящей работы - исследование спектров электролюминесценции мощных диодов в ближней ультрафиолетовой области и их сравнение с синими и фиолетовыми СД, имеющими схожую структуру. Работа продолжает исследования мощных СД [5].

\section{2. Объекты и методика исследований}

\section{1. Методика измерений}

Для измерения спектров электролюминесценции использовалась автоматизированная установка на основе монохроматора МДР-12. Регистрация сигнала осуществлялась фотоэлектронным умножителем ФЭУ-79 в режиме счета фотонов. Методика позволяет измерять спектры излучения СД в широком диапазоне токов от единиц мкА до $1 \mathrm{~A}$.

\section{2. Конструкция мощных светодиодов}

Исследованные мощные СД были разработаны отечественной фирмой НПЦ ОЭП „Оптэл“ на основе кристаллов с $p$-n-гетероструктурами типа InGaN/AlGaN/GaN с множественными квантовыми ямами (МКЯ) InGaN/GaN. Кристаллы были предоставлены фирмой SemiLEDs (Тайвань) и имели размеры $1.07 \times 1.07 \mathrm{MM} \quad$ (размеры активной области $0.97 \times 0.97$ мм). Они были выращены методом газофазной эпитаксии из металлоорганических соединений на сапфировых подложках $[6,7]$, отделены от этих подложек с использованием технологии „lift-off“ и смонтированы на медную пластину, обладающую высокой теплопроводностью. Такая технология позволяет повысить внешний квантовый выход излучения, уменьшив концентрацию дефектов в слое $\mathrm{GaN}$, и обеспечить вертикальное 


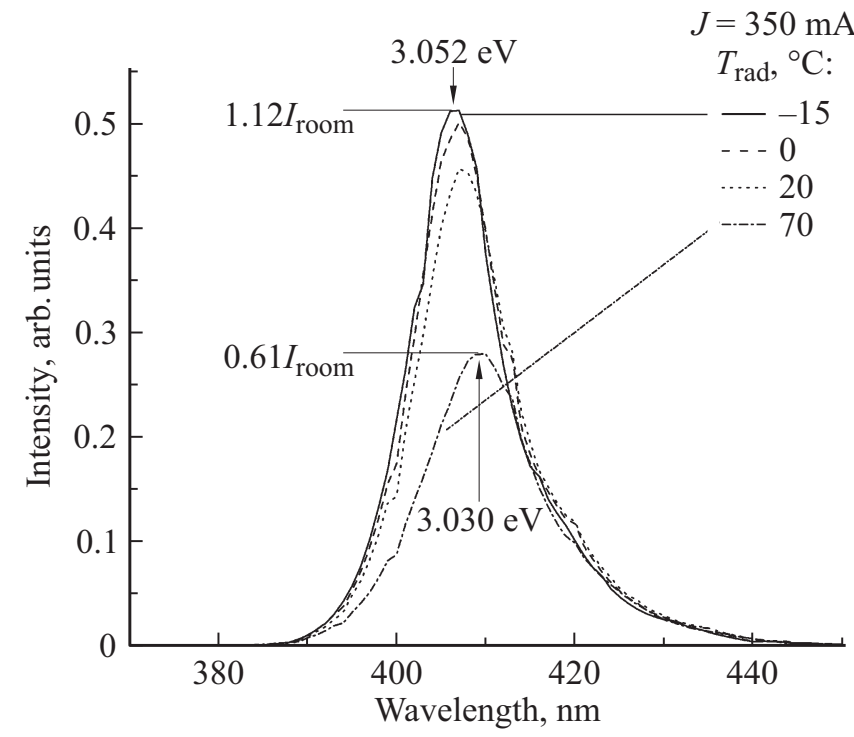

Рис. 1. Спектры излучения фиолетового СД при температурах от -15 до $+70^{\circ} \mathrm{C}$ при токе $350 \mathrm{MA}, T_{\text {rad }}$ - температура радиатора.

протекание тока, создав контакты на противоположных гранях. Далее кристаллы монтировались в теплоотводящий корпус с большим диаметром основания.

\section{3. Спектры электролюминесценции}

\section{1. Зависимость спектров излучения от тока и температуры}

Спектры излучения были измерены в диапазоне токов $J=50-350$ мА. На рис. 1 показаны измеренные спектры для одного из СД.

Температурные измерения проводились с помощью элемента Пельтье, нагревающего или охлаждающего радиатор, к которому крепился СД. Температура радиатора $T_{\text {rad }}$ изменялась от -15 до $+70^{\circ} \mathrm{C}$. Для всех образцов с понижением $T$ наблюдались смещение положения максимума на 22-32 мэВ в коротковолновую область, а также уменьшение ширины линий на половине высоты на 18-24 мэВ. Максимальная интенсивность спектров излучения СД при $T=-15^{\circ} \mathrm{C}$ была на $10-13 \%$ больше аналогичной величины при комнатной температуре $I_{\text {room }}$.

$\mathrm{C}$ увеличением температуры до $70^{\circ} \mathrm{C}$ максимальная интенсивность спектров синих СД составляла 70-74\% от максимальной интенсивности при комнатной температуре, для фиолетовых СД интенсивность уменьшалась до $58-61 \%$.

\section{2. Основная линия спектров люминесценции}

Спектры электролюминесценции СД при комнатной температуре имели основные пики с максимумами при энергиях от 2.71 до 3.35 эВ. Они были разделены на следующие группы: синие - от 2.71 до 2.74 эВ; фиолетовые - от 3.01 до 3.05 эВ; длинноволновые УФ от 3.18 до 3.20 эВ; коротковолновые УФ - от 3.33 до 3.35 эВ.

Форма спектров была описана в рамках модели, учитывающей двумерную плотность состояний и флуктуации потенциала в активной области рекомбинации, с характерным экспоненциальным спадом (энергия $E_{0}$ ) в длинноволновой области, а также функцию заполнения состояний с экспоненциальным наклоном (энергия $E_{1}$ ) в коротковолновой области [8].

Основная линия спектров излучения описывалась формулой модели [8]:

$$
I(\hbar \omega)=N^{2 \mathrm{D}}\left(\hbar \omega, E_{g}^{*}, E_{0}\right) f_{c}\left(1-f_{v}\right),
$$

где $I$ - интенсивность, $\hbar \omega-$ энергия фотона, двумерная комбинированная плотность состояний $N^{2 \mathrm{D}}$ зависит от эффективной ширины запрещенной зоны $E_{g}^{*}$, от параметра экспоненциального спада в длинноволновой области $E_{0}$, и функций заполнения состояний электронами в зонах проводимости, $f_{c}$, и валентной, $f_{v}$. Функции заполнения, в свою очередь, зависят от положения квазиуровней Ферми и температуры $T$ - от параметpa $E_{1}=m k T$. Качественное применение теоретической формулы к экспериментальным данным показано на вставке к рис. $2, b$.

Параметр $m$ в формуле $E_{1}=m k T$ для всех образцов при малых токах был равен 0.94-1.03, что близко к теоретической единице. Это достаточно хорошее согласие позволило фиксировать параметр $E_{1}$ в формуле для описания спектров [8] и оценить нагрев активной области СД при увеличении тока $J$. Величина $E_{1}$ линейно зависела от потребляемой СД мощности $W=J V$, т.е. $T \propto W$. Была определена величина теплового сопротивления, которая для всех СД равнялось $40-51 \mathrm{~K} / \mathrm{B}$.

Результаты обработки спектров для одного из СД представлены в таблице. По изменению параметра $E_{1}=k T$ был оценен нагрев структур. Заметим, что для синих, фиолетовых и длинноволновых УФ (максимум пика до 3.2 э) светодиодов значения этого параметра при низких токах соответствуют теоретическому, $\sim 25.3$ мэВ при комнатной температуре (см. рис. 2, $b$ ). С увеличением тока происходит нагрев структур СД, и при токе $350 \mathrm{MA}$ изменение температуры составляло $\Delta T \approx 40-50^{\circ} \mathrm{C}$.

Результаты обработки спектра одного из светодиодов

\begin{tabular}{r|c|c|c|c|c}
\hline$J$, мА & $V, \mathrm{~B}$ & $\Delta(\hbar \omega)_{1 / 2}$, эВ & $\hbar \omega_{\max }$, эВ & $E_{0}$, эВ & $E_{1}$, эВ \\
\hline 350 & 3.479 & 0.188 & 3.021 & 0.0562 & 0.0286 \\
200 & 3.312 & 0.164 & 3.017 & 0.0572 & 0.0278 \\
100 & 3.151 & 0.138 & 3.009 & 0.0586 & 0.0272 \\
50 & 3.040 & 0.132 & 3.005 & 0.0578 & 0.0264 \\
35 & 3.000 & 0.13 & 3.002 & 0.0569 & 0.0255 \\
20 & 2.943 & 0.13 & 3.001 & 0.0594 & 0.0253 \\
10 & 2.896 & 0.134 & 3.000 & 0.0608 & 0.0252
\end{tabular}



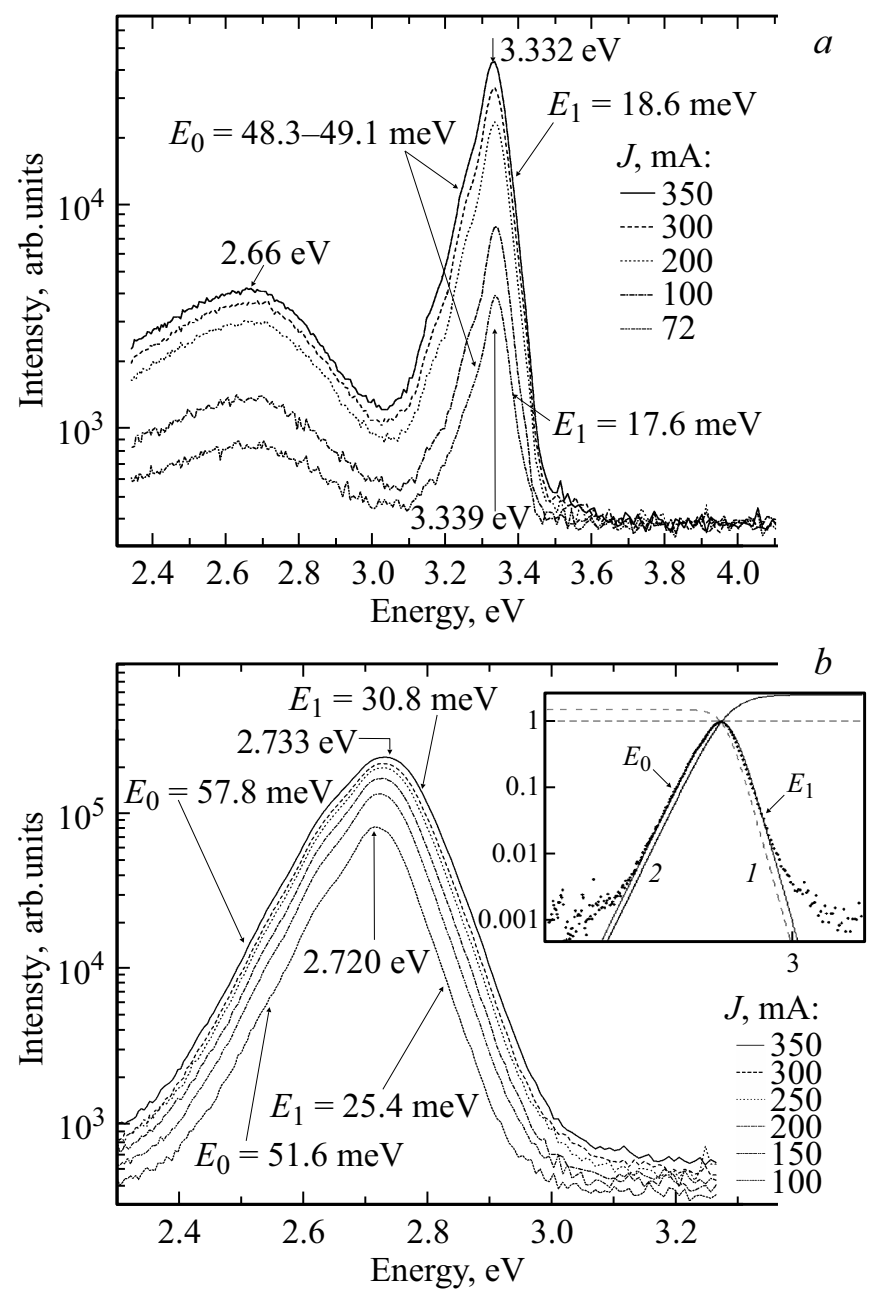

Рис. 2. Спектры электролюминесценции коротковолнового УФ диода $(a)$ и синего СД $(b)$. На вставке $(b)$ : точки эксперимент, линии - расчет в модели [10] множителя $f_{c}\left(1-f_{v}\right)(1)$ и множителя $N^{2 \mathrm{D}}(2)$.

Коротковолновые УФ диоды, максимум излучения которых лежал около $3.33-3.35$ эВ, имели значения параметра $E_{1}$, отличающиеся от $k T$ : изменяются от 17.3 до 18.6 мэВ с ростом тока (рис. 2,a). Причиной низких значений $E_{1}$ и соответственно резкого спада может служить поглощение излучения более широкозонными слоями гетероструктуры - ширина запрещенной зоны $\mathrm{GaN} \sim(3.4-3.5)$ эВ при комнатной температуре.

Из рис. $2, a$ видно, что при энергиях $\sim 3.5$ эВ спектры резко обрываются. Таким образом, спектры коротковолновых УФ диодов искажены поглощением в других областях структуры. Параметр $\Delta(\hbar \omega)_{1 / 2}$ - ширина линий на половине высоты - изменялся вследствие нагрева структур с увеличением $J$. Для синих СД ширина изменялась от 19 до 25 нм, для фиолетовых и длинноволновых УФ - от 14 до 23 нм; для коротковолновых УФ почти не изменялась, (изменение от 10 до $11 \mathrm{Hм}$ ).

Величина $E_{0}$ изменялась при изменении тока. Для синих и фиолетовых СД этот параметр изменялся от 50 до 62 мэВ, для длинноволновых УФ - от 50 до 56 мэВ, а для коротковолновых УФ - от 46 до 49 мэВ (см. рис. 2, $a, b)$. Эта особенность спектров СД сильнее проявляется в гетероструктурах из нитридов, чем из арсенидов и фосфидов, вследствие бо́льших флуктуаций потенциала.

В синих СД заметно больше содержание In по сравнению с УФ СД; следовательно, и флуктуации потенциала больше. Поэтому для синих светодиодов величина $E_{0}$ больше, чем для УФ.

\section{3. Дополнительный пик в длинноволновой области}

В спектрах люминесценции фиолетовых СД (рис. 3, линейный масштаб) и УФ СД (рис. 2, $a$, полулогарифмический масштабе) был обнаружен дополнительный пик в длинноволновой области. Природа этого пика может быть связана с глубокими примесными уровнями в запрещенной зоне $\mathrm{GaN}$. На образцах первой партии (фиолетовых и длинноволновых УФ) максимум этого пика лежит около 2.13-2.22 эВ, что соответствует желтой люминесценции. Спектры излучения диодов последней партии (коротковолновая УФ область) имеют дополнительный пик около 2.66-2.68 эВ, соответствующий синей области.

Согласно [9] излучение в желтой области связано с глубокими акцепторами атомов углерода $\mathrm{C}_{\mathrm{N}}$ в слое $\mathrm{GaN}$, а излучение в синей области - с комплексами доноров $\mathrm{C}_{\mathrm{N}}-\mathrm{Si}_{\mathrm{Ga}}$ в $\mathrm{GaN}$. Желтое излучение доминирует в спектрах образцов первой партии, в них синей линии нет. Отношение интенсивностей дополнительного пика к основному увеличивается с продвижением в глубь ультрафиолетовой области: для образцов длинноволнового УФ диапазона оно достигает $1.7 \%$, а для коротковолнового УФ- $9.8 \%$.

На рис. 3 заметна слабая дублетная линия около 700 нм, являющаяся результатом люминесценции оста-

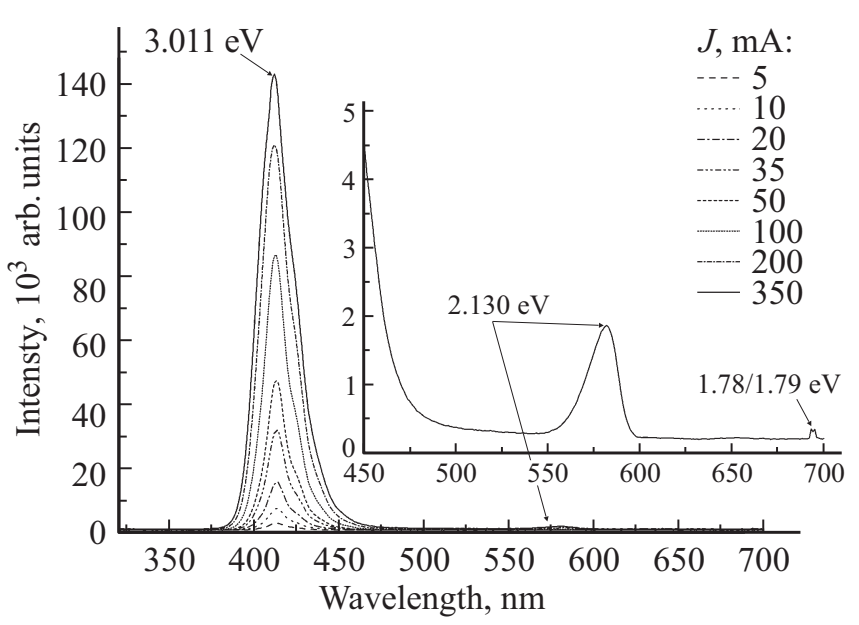

Рис. 3. Спектры электролюминесценции фиолетового светодиода. На вставке - часть спектра в увеличенном масштабе. 
точных примесных ионов $\mathrm{Cr}^{3+}$ в сапфировой подложке [10].

\section{4. Мощность и эффективность излучения}

Зависимости мощности излучения от тока для фиолетовых СД и длинноволнового УФ СД представлена на рис. 4. Видно, что максимальная мощность падает с продвижением в глубь УФ диапазона и достигает максимального значения 233 мВт при токе 350 мА для фиолетового СД (длина волны максимума $\left.\lambda_{\max }=412 \mathrm{Hм}\right)$ и 64.8 мВт при токе 350 мА для УФ СД $\left(\lambda_{\max }=389\right.$ нм$)$.

Из зависимости внешнего квантового выхода излучения от тока видно (рис. 5), что с продвижением в УФ область уменьшается как его максимум (от 23.3 до

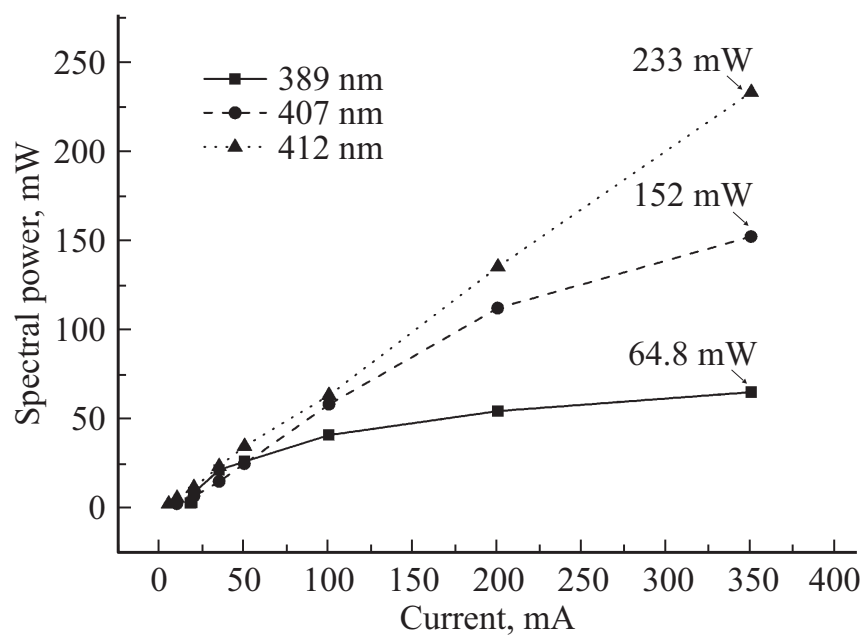

Рис. 4. Спектральная мощность фиолетовых и длинноволнового УФ светодиодов.

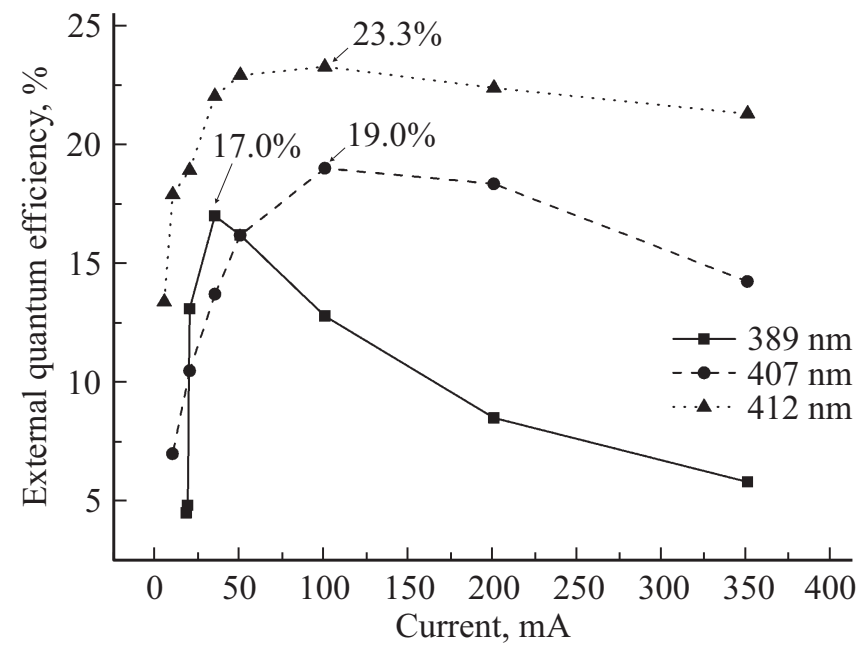

Рис. 5. Зависимость внешнего квантового выхода излучения от тока для фиолетовых и длинноволнового ультрафиолетового светодиодов.
$17.0 \%$ ), так и положение максимума (от 100 до 35 мА) для диодов с $\lambda_{\max }=412$ и $389 \mathrm{Hм}$, соответственно.

\section{5. Обсуждение результатов}

Эффективную ширину запрещенной зоны $\left(E_{g}^{\mathrm{eff}}\right)$ в квантовых ямах можно оценить из спектров излучения в широком диапазоне токов. $E_{g}^{\mathrm{eff}}$ для синих СД изменяется от 2.72 до 2.78 эВ, для фиолетовых — от 3.03 до 3.09 эВ, для длинноволновых УФ - от 3.14 до 3.21 эВ, для коротковолновых УФ - от 3.32 до 3.34 эВ. При небольших токах через $p-n$-гетероструктуру свободные носители заряда заполняют локализованные состояния в квантовых ямах. При этом положение максимума спектра почти не изменяется, а внешний квантовый выход увеличивается с увеличением пропускаемого через образец тока до некоторого значения. Достижение максимума внешнего квантового выхода означает, что все локализованные состояния заполнены. При дальнейшем увеличении тока заполняются делокализованные состояния, вследствие чего наблюдается уменьшение эффективности и смещение положения максимума. Глубина квантовых ям $\mathrm{In}_{x} \mathrm{Ga}_{1-x} \mathrm{~N}$ уменьшается при продвижении спектров СД в УФ область, и максимум квантового выхода излучения смещается в область меньших токов.

Следует отметить роль глубоких уровней в слоях $\mathrm{GaN}$, которые дают дополнительную линию в спектрах электролюминесценции. Как было отмечено, отношение интенсивностей этой линии и основной увеличивается с продвижением в УФ сторону и достигает 9.8\% для диода, излучающего около 370 нм. Поэтому при выращивании структур для СД необходимо понять причину появления этих уровней в люминесценции.

Обращают на себя внимание спектры диодов из группы коротковолновых УФ, излучающих около $3.33-3.35$ эВ и имеющих более резкий экспоненциальный спад в коротковолновой области (параметр $E_{1}$ заметно меньше $k T$ ). С одной стороны, из-за частичного поглощения слоями $\mathrm{GaN}$ неизбежно падение эффективности излучения СД, но с другой стороны, это поглощение искусственно улучшает другую характеристику уменьшает ширину линии. Как было отмечено выше, ширина линии на половине высоты почти не изменяется с повышением тока и равна 10-11 нм.

\section{6. Заключение}

Спектры электролюминесценции мощных ( 1 Вт) коротковолновых светодиодов на основе $p-n$-гетероструктур типа InGaN/AlGaN/GaN с МКЯ InGaN/GaN имели максимумы в диапазоне длин волн от ближнего ультрафиолетового (370 нм) до синего излучения (460 нм).

Спектры излучения в диапазоне токов от 1 до 350 мА описаны моделью, учитывающей двумерную комбинированную плотность состояний и флуктуации потенциала. Параметр $E_{1}$ коротковолнового экспоненциаль- 
ного спада спектров ультрафиолетовых диодов меньше энергии $k T$, что объясняется поглощением излучения в широкозонных слоях гетероструктуры.

В спектрах излучения обнаружена дополнительная длинноволновая линия в области энергий 2.2-2.6 эВ, которая объяснена наличием глубоких уровней примесей $\mathrm{C}_{\mathrm{N}}$ (желтая область) и комплексов $\mathrm{C}_{\mathrm{N}}-\mathrm{Si}_{\mathrm{Ga}}$ (синяя область) в слоях $\mathrm{GaN}$. Относительная интенсивность этих линий увеличивается с продвижением основного максимума в коротковолновую область.

\section{Список литературы}

[1] Handbook of Crystal Growth: Thin Films and Epitaxy, ed. by T.F. Kuech, 2nd edn (2015) p. 683.

[2] M.E. Aumer, S.F. Le Boeuf, F.G. Mc Intosh, S.M. Bedair. Appl. Phys. Lett., 75, 3315 (1999).

[3] Y.-A. Chang, S.-H. Yen, T.-C. Wang, H.-C. Kuo, Y.-K. Kuo, T.-C. Lu, S.-C. Wang. Semicond. Sci. Technol., 21, 598 (2006).

[4] Л.М. Коган, А.А. Колесников, А.Н. Туркин. Светотехника, № 2, 57 (2016).

[5] Л.П. Авакянц, А.Э. Асланян, П.Ю. Боков, В.В. Волков, И.С. Матешев, А.Н. Туркин, А.В. Червяков, А.Э. Юнович. Уч. записки физ. факультета МГУ, № 3, 163401 (2016).

[6] D. Amabile, R.W. Martin, T. Wang, M.A. Whitehead, P.J. Parbrook. Phys. Status Solidi C, 0 (7), 2478 (2003).

[7] C.H. Chen, L.Y. Huang, Y.F. Chen, H.X. Jiang, J.Y. Lin. Appl. Phys. Lett., 80, 1397 (2002).

[8] М.Л. Бадгутдинов, А.Э. Юнович. ФТП, 42 (4), 438 (2008).

[9] Sayre G. Christenson, Weiyu Xie, Y.Y. Sun, S.B. Zhang. J. Appl. Phys., 118, 135708 (2015).

[10] В.Е. Кудряшов, С.С. Мамакин, А.Э. Юнович. Письма ЖТФ, 25 (13), 68 (1999).

Редактор Л.В. Шаронова

\section{Luminescence spectra of high-power violet and ultraviolet light emitting diodes based on gallium nitride}

V.V. Volkov ${ }^{1}$, L.M. Kogan ${ }^{2}$, A.N. Turkin ${ }^{1}$, A.E. Yunovich ${ }^{\mathbf{1}}$

${ }^{1}$ Lomonosov Moscow State University

(Faculty of Physics),

119991 Moscow, Russia

2 Scientific-Productional Center „Optel“, 105187 Moscow, Russia

Abstract Electroluminescence spectra of high-power light emitting diodes based on $p-n$-heterostructures of InGaN/AlGaN/GaN type were studied. Diodes radiated in visible short-wavelength and ultraviolet spectral regions (from 370 to $460 \mathrm{~nm}$ ). The shape of spectra was described by the model which takes into account two-dimensional combined density of states and potential fluctuations. In the radiation spectra additional long-wavelength peaks were found. The radiation power of violet and ultraviolet diodes reached $233 \mathrm{~mW}$ at the current of $350 \mathrm{~mA}$, the external quantum efficiency reached to $23 \%$ at the maximum (near the current of $100 \mathrm{~mA}$ ). 